\title{
US dietary guidelines: is saturated fat a nutrient of concern?
}

\author{
Zoe Harcombe
}

Independent Researcher, UK

Correspondence to

Dr Zoe Harcombe;

zoe@theobesityepidemic.org

Accepted 24 July 2018

Published Online First

14 August 2018
Check for updates

(c) Author(s) (or their employer(s)) 2019. No commercial re-use. See rights and permissions. Published by BMJ.

To cite: Harcombe $Z$. Br J Sports Med

2019:53:1393-1396.

\section{ABSTRACT}

US public health dietary advice was announced by the Select Committee on Nutrition and Human needs in 1977 and was followed by UK public health dietary advice issued by the National Advisory Committee on Nutritional Education in 1983. Dietary recommendations in both cases focused on reducing dietary fat intake; specifically to (i) reduce overall fat consumption to $30 \%$ of total energy intake and (ii) reduce saturated fat consumption to $10 \%$ of total energy intake. The recommendations were an attempt to address the incidence of coronary heart disease. These guidelines have been reiterated in the Dietary Guidelines for Americans since the first edition in 1980. The most recent edition has positioned the total fat guideline with the use of 'Acceptable Macronutrient Distribution Ranges'. The range given for total fat is $20 \%-35 \%$ and the AMDR for saturated fat is given as $<10 \%$ - both as a percentage of daily calorie intake. In February 2018, the Center for Nutrition Policy and Promotion announced 'The US Departments of Agriculture and Health and Human Services currently are asking for public comments on topics and supporting scientific questions to inform our development of the 2020-2025 Dietary Guidelines for Americans'. Public comments were invited on a number of nutritional topics. The question asked about saturated fats was: 'What is the relationship between saturated fat consumption (types and amounts) during adulthood and risk of cardiovascular disease?' This article is a response to that question.

\section{INTRODUCTION: THE DIETARY GUIDELINES}

US public health dietary advice was announced by the Select Committee on Nutrition and Human needs in $1977^{1}$ and was followed by UK public health dietary advice issued by the National Advisory Committee on Nutritional Education in 1983. ${ }^{2}$ Dietary recommendations in both cases focused on reducing dietary fat intake; specifically to (i) reduce overall fat consumption to $30 \%$ of total energy intake and (ii) reduce saturated fat consumption to $10 \%$ of total energy intake.

The recommendations were an attempt to address the incidence of coronary heart disease (CHD). Both documents acknowledged that the evidence was not conclusive. Hegsted's introduction to the Dietary Goals for The United States noted 'there will undoubtedly be many people who will say we have not proven our point'. ${ }^{1}$ The UK publication referred to 'a strong consensus of opinion'.2
These guidelines have been reiterated in the Dietary Guidelines for Americans since the first edition in $1980 .{ }^{3}$ The most recent edition has positioned the total fat guideline with the use of 'Acceptable Macronutrient Distribution Ranges' (AMDRs). The range given for total fat is $20 \%-35 \%$ and the AMDR for saturated fat is given as $<10 \%$-both as a percentage of daily calorie intake. ${ }^{4}$

In February 2018, the Center for Nutrition Policy and Promotion announced 'The US Departments of Agriculture (USDA) and Health and Human Services (HHS) currently are asking for public comments on topics and supporting scientific questions to inform our development of the 2020-2025 Dietary Guidelines for Americans'. Public comments were invited on a number of nutritional topics. The question asked about saturated fats was: 'What is the relationship between saturated fat consumption (types and amounts) during adulthood and risk of cardiovascular disease? ? $^{5}$ This article is a response to that question.

\section{THE FACTS ABOUT FAT}

Dietary fat, especially saturated fat, has been the subject of health warnings from public health organisations for 40 years. It is pertinent to counterbalance these negative messages with some facts about fat and saturated fat, which are less well known:

1. Human beings must consume fat; we die without doing so. The word 'essential' in nutrition means something that we must consume. There are two essential fats (omega-3 and omega-6) and four fat soluble vitamins (A, D, E and K).

2. All food that contains fat contains all three natural fats: saturated; monounsaturated and polyunsaturated. It is impossible to consume unsaturated fat without saturated fat, or vice versa, in natural food. This second fact also establishes that saturated fat is no more synonymous with animal foods than unsaturated fat is synonymous with plant foods. All food that contains fat-plant or animal in origin-contains all three natural fats; the proportions vary.

3. Dairy is the only food group that contains more saturated than unsaturated fat. While there are individual substances (eg, coconut oil) that contain more saturated than unsaturated fat, there is only one food group that is primarily saturated fat. The US 'My Plate' inexplicably defines food groups as: fruit; vegetables; grains; protein and dairy. Protein is a macronutrient. It is found in every food other than sucrose/pure fats. Protein is not a food group and the list of other food groups is incomplete. A better list of food groups would be: meat; fish; eggs; dairy; 
vegetables; fruit; nuts and seeds; legumes (beans, pulses and so on) and grains. The only one of these, for which the fat content is predominantly saturated, is dairy. Meat, fish, eggs, nuts, seeds and even lard all have more unsaturated than saturated fat.

Given that human beings must consume fat to survive, and given that saturated fat cannot be avoided, it would be illogical for the same natural food to be both harmful and healthful: 'Using a $100 \mathrm{~g}$ steak, as an example, with $5.4 \mathrm{~g}$ of fat, it is difficult to accept that the 39\% of the fat which is saturated is damaging to the cardiovascular system while the 61\% of the fat which is unsaturated is protective. Keeping in mind that the total fat content of the steak will provide all but 3 of the 13 vitamins and 16 minerals that are a pre-requisite for the maintenance of good health'. ${ }^{6}$

The beef-steak facts may elicit surprise. So might the fact that, gram for gram, olive oil ${ }^{7}$ has 14 times the total fat of that piece of trimmed beef sirloin $^{8}$ and 7 times the saturated fat. A counter may be that large quantities of olive oil are rarely consumed. A further retort could be that one tablespoon of olive oil has more saturated fat than a $100 \mathrm{~g}$ pork chop. ${ }^{9}$ And the oily fish, mackerel, ${ }^{10}$ which we are advised to eat, has twice the total fat and one and a half times the saturated fat of that red meat we are told to avoid. ${ }^{8}$ Facts about nutrition can make a mockery of dietary guidelines.

\section{THE RANDOMISED CONTROLLED TRIAL EVIDENCE}

My doctoral thesis was entitled 'An examination of the randomised controlled trial (RCT) and epidemiological evidence for the introduction of dietary fat recommendations in 1977 and 1983: A systematic review and meta-analysis'. RCTs are superior to epidemiological studies in the hierarchy of evidence. A systematic review and meta-analysis of RCTs is better still. ${ }^{11} 12$ This was thus the logical place to start the investigation. The primary outcome measure was set as mortality-all-cause and from heart disease-as this is the most important outcome measure to examine. There is no point dying less from one condition to die more from another.

The first paper published from my $\mathrm{PhD}$ was a systematic review and meta-analysis of the RCTs available at the time the 1977 dietary committee was deliberating. ${ }^{13}$ We found that there were exactly the same number of deaths in the control and intervention groups and no significant differences in deaths from CHD. We also found that fewer than 2500 sick men had been studied (no women and no healthy men), with no evidence in support of introducing dietary fat guidelines, and yet 'Dietary recommendations were introduced for 220 million US and 56 million UK citizens by 1983, in the absence of supporting evidence from RCTs' ${ }^{13}$

During media discussions on the day of publication, we were surprised by the readiness of Public Health England (the UK dietary guideline setting body) to accept that the evidence was not present at the time the guidelines were introduced. Our follow-up paper found that, three decades on, the case for dietary fat restrictions had still not been made. ${ }^{14}$ This paper reported that women and healthy men were now included in RCTs available for review. However, the pooled RCTs again found no significant differences in all-cause or CHD mortality. Additionally, the pooled RCTs revealed that only 1 of the 10 RCTs included healthy men and women and thus, even if results had been found, they would still not have been generalisable to the whole population. ${ }^{15}$
The full papers detail the interventions. Some were to reduce fat and some were to modify fat (to replace saturated fat with unsaturated fat). None made a case for change individually and there was no case for change collectively in meta-analysis. A number of authors cautioned that their vegetable oil interventions were potentially harmful or toxic.

An additional valuable finding from both papers was that 'Mean serum cholesterol levels decreased in all intervention groups and all but one control group. The reductions in mean serum cholesterol levels were significantly greater in the intervention groups; this did not result in significant differences in $\mathrm{CHD}$ or all-cause mortality' (abstract). ${ }^{14}$ These papers undermined the diet-heart-cholesterol hypothesis as well as finding no evidence for total or saturated fat reduction, or dietary modification to replace saturated with unsaturated fat.

\section{THE EPIDEMIOLOGICAL EVIDENCE}

Notwithstanding that epidemiological evidence is weaker than that of RCTs, for completeness, my $\mathrm{PhD}$ sought to examine the epidemiological evidence available at the time dietary guidelines were introduced in the USA (and subsequently the UK) and the epidemiological evidence available today. The paper on the epidemiological evidence at the time reported that there were six studies to systematically review. These studies could not be subjected to meta-analysis, as the data were not conducive. The conclusion of the paper was 'None of the six studies found a significant relationship between $C H D$ deaths and total dietary fat intake. One of the six studies found a correlation between CHD deaths and saturated dietary fat intake across countries; none found a relationship between CHD deaths and saturated dietary fat in the same population' (abstract). ${ }^{16}$

The one study that found a relationship between CHD deaths and saturated fat intake across countries was the well-known and invariably referenced Seven Countries Study. ${ }^{17}$ In this study, Keys asserted that smoking, activity levels/exercise and weight played no part in CHD. This study has been afforded huge regard in its contrary (among five peer papers) finding on saturated fat when it is known to be wrong on three other major risk factors. The most significant limitation of the study was that it was an intercountry comparison, rather than a $\mathrm{CHD} / \mathrm{CHD}$-free comparison. Men (and it was only men) who developed CHD in Japan were compared with men who developed CHD in the USA, as opposed to men who developed CHD in Japan being compared with men who did not develop CHD in Japan. This introduced substantially more confounding factors, including geography; lifestyle; Gross Domestic Product; climate; politics; other aspects of national diet; national health provision and so on.

Epidemiological evidence available in 2016 fared little better. In the fourth part of my PhD, I concluded that 'Epidemiological evidence to date found no significant difference in CHD mortality and total fat or saturated fat intake and thus does not support the present dietary fat guidelines. The evidence per se lacks generalisability for population-wide guidelines' (abstract). ${ }^{18}$

\section{OTHER META-ANALYSES}

To present the findings of my $\mathrm{PhD}$ team in context, we reviewed other systematic reviews and meta-analyses that had placed heart disease and mortality as the key outcome measures.

A number of meta-analyses of RCTs, examining dietary fat and mortality, have been undertaken by other authors. ${ }^{19-21}$ One meta-analysis of prospective cohort studies has been undertaken by other authors. ${ }^{22}$ Two additional meta-analyses reviewed both 
RCTs and prospective cohort studies. ${ }^{23}{ }^{24}$ Skeaff and Miller sought to summarise the evidence from cohort studies and RCTs of the relation between dietary fat and risk of CHD. Their conclusion was 'Intake of total fat was not significantly associated with CHD mortality. Intake of total fat was also unrelated to CHD events' (p.175). ${ }^{23}$ Chowdhury et al set out to summarise evidence between fatty acids and coronary disease. Their review examined saturated, monounsaturated, polyunsaturated and trans fats, while also reviewing individual chain length fatty acids, palmitic (C16:0) and margaric (C17:0) as examples. The conclusion was 'Current evidence does not clearly support cardiovascular guidelines that encourage high consumption of polyunsaturated fatty acids and low consumption of total saturated fats' (p.398). ${ }^{24}$

Table 7.1 in the review paper from my PhD summarised the findings from other meta-analyses of RCTs and/or prospective cohort studies. ${ }^{25}$ There were 39 reports of risk ratios from meta-analysis with $95 \%$ CIs; 35 of which were non-significant. The fact that so much research has been undertaken, examining total fat, types of fat, mortality and heart disease, and that the vast majority has found nothing of any significance, is important.

One of the four significant findings related to trans fats, rather than total or saturated fat. Trans fat intake was positively associated with coronary disease. ${ }^{24}$ Another of the significant findings came from the study of the impact of replacing saturated fat with polyunsaturated fat, ${ }^{21}$ which was criticised $^{26}$ for excluding two studies that would have moderated this conclusion ${ }^{27} 28$ and including a favourable, but non-randomised, non-controlled, crossover trial excluded by the other meta-analyses. ${ }^{29}$

The Cochrane reviews, ${ }^{20} 30$ one an update of the other, provided the only ostensibly credible findings against saturated fat for cardiovascular disease (CVD) events, but not for total mortality, CVD mortality, fatal myocardial infarction (MIs), non-fatal MIs, strokes, CHD mortality, CHD events or the diagnosis of diabetes. The prima facie contradiction of a finding for CVD events, but not for many outcomes included in CVD events-CVD deaths, non-fatal MIs and strokes—can be explained by the many softer outcomes included in CVD events (eg, angina and peripheral vascular events and unplanned interventions such as angioplasty). The Cochrane reviews included four small studies (646 people in total), not included in any other meta-analysis, which were primarily studies of: diabetes ${ }^{31}$; skin cancer $^{32}$; hypercholesterolaemia ${ }^{33}$ and glucose intolerance, ${ }^{34}$ but for which unpublished, non-peer-reviewed CVD event information was obtained. No study of healthy people of both genders was included and thus even this one apparent finding, for events alone, lacks generalisability.

Hooper et al suggested that there may be a small reduction in cardiovascular risk with reduction of dietary saturated fat intake. ${ }^{30}$ However, the findings were inconsistent between studies (shown by the $\mathrm{I}^{2}$ test of $65 \%$ ). When a sensitivity test included only the RCTs that had significantly reduced saturated fat (>52000 participants), the CVD events finding reduced from $17 \%$ to $9 \%$ and was no longer statistically significant (table 8, p.121). ${ }^{30}$

Seemingly having ignored that the only 'finding' was in fact non-significant and thus there were no findings, the paper continued to suggest that replacing energy from saturated fat with polyunsaturated fat 'appears to be a useful strategy, and replacement with carbohydrate appears less useful' (p.2) (10 $^{30}$ and replacement with monounsaturated fat unclear. Of the 11 interventions contributing to this conclusion, only 1 documented both saturated fat reduction and reported that this was mainly replaced with polyunsaturated fat. ${ }^{35}$

Even if there were any findings in favour of polyunsaturated fat, it would be important to differentiate between polyunsaturated fats. The Diet and Reinfarction Trial provided early evidence for the benefit of omega-3 polyunsaturated fat, naturally abundant in fish. ${ }^{36}$ The only significant finding from this RCT was that all-cause mortality was lower for those following the fish advice, which was to increase fatty fish intake to at least two portions (200-400 g) weekly. This significant finding was explored further by the research team, but not found to be replicated. ${ }^{37}$ Omega- 6 polyunsaturated fats have proinflammatory properties, which can be mitigated by omega-3 intake, ${ }^{38}$ but any dietary advice on polyunsaturated fats needs to be specific and evidence based.

The American Heart Association (AHA) advisory report, ${ }^{39}$ which was published in June 2017, repeated the bias of Mozaffarian $e t a l^{21}$ by also excluding the same two studies that did not support replacing saturated fat with unsaturated fat ${ }^{27} 28$ and by excluding another study that did not support the prounsaturated fat message ${ }^{15}$ and by including the same favourable, but non-randomised, non-controlled, crossover trial-the Finnish Mental Hospital study. ${ }^{29}$ The AHA report tried to rationalise exclusions, but the bias is clear to see to any independent researcher and the polyunsaturated fat/industry conflicts with the paper were not fully declared. ${ }^{40}$

Dietary fat guidelines were introduced with the ambition of reducing deaths from CHD. In conclusion of the pool of evidence provided by many researchers in this field, no meta-analysis of RCTs and/or prospective cohort studies has found any significant difference for dietary fat interventions and all-cause mortality or deaths from $\mathrm{CHD}$, or associations with dietary fat and CHD mortality. ${ }^{13} 19-2430$

\section{A WAY FORWARD}

The Dietary Guidelines for Americans documented the sources of saturated fat in the American diet (figs. 3 and 4, p.26). ${ }^{41}$ Pizza, desserts, candy, potato chips, pasta, tortillas, burritos and tacos accounted for $32.6 \%$ of saturated fat consumed in the diets of US citizens aged 2 years and older; $9.3 \%$ of dietary saturated fat came from sausages, frankfurters, bacon, ribs and burgers; $12.8 \%$ came from chicken and mixed chicken dishes, beef and mixed beef dishes, and eggs and mixed egg dishes. A further $24.5 \%$ was unaccounted for and collated as 'all other food categories'; likely including, if not predominantly being, processed foods. The natural foods listed were cheese, milk, butter, nuts and seeds which collectively accounted for $20.8 \%$ of saturated fat intake. It would have been ideal for unprocessed chicken, beef and eggs to have been separated from processed meals containing these ingredients. The diagram presented in the Dietary Guidelines is clear nonetheless. Processed foods account for the majority of saturated fat intake in the diets of Americans.

There is opportunity for strong agreement among health professionals. If the public health message were revised to advise citizens to eat natural food and not processed food, saturated fat intake might fall although the health benefit would likely be due to the concomitant reduction in sucrose, trans fats and other processed ingredients deleterious to human health. ${ }^{42}$ Human beings evolved to eat foods available from the natural environment. ${ }^{43}$ It does not seem logical to advise populations away from carcass meat, dairy, eggs, nuts and seeds, in the name of saturated fat, when the modern processed foods, cookies, cakes, pizza, 
desserts and ready meals are more sensibly related to modern illness. $^{6}$

\section{CLOSE}

The USDA and HHS asked for public comments in response to the following question: 'What is the relationship between saturated fats consumption (types and amounts) during adulthood and risk of CVD? ${ }^{36}$ The answer is that there is adequate evidence of no relationship between saturated fat consumption during adulthood and actual CVD outcomes. There is also strong agreement from robust meta-analyses of no relationship between saturated fat consumption and: total mortality; CVD mortality; fatal MIs; non-fatal MIs; strokes; CHD mortality or CHD events.

\section{What is already known?}

- Dietary recommendations were introduced in the US (1977) and in the UK (1983) to (i) reduce overall fat consumption to $30 \%$ of total energy intake and (ii) reduce saturated fat consumption to $10 \%$ of total energy intake.

- The 2015 Dietary Guidelines for Americans have revised the total fat recommended intake using a range (20-35\%), rather than a maximum of $30 \%$. The saturated fat recommendation has been reinforced as $<10 \%$ of daily calorie intake

\section{What are the new findings?}

- Four systematic reviews have been undertaken of the RCT and prospective cohort study evidence available to the dietary committees and that currently available. This paper presents the totality of the evidence, then and now, to show that the extant dietary fat guidelines were and are without evidence base.

- Even if the evidence had been overwhelming, the limitations of the studies were so great that the evidence could not be relied upon.

- Other meta-analyses of RCTs and/or prospective cohort studies have reported 39 risk ratios between them: 35 of which were not significant. Not one of the four significant results found any relationship between dietary fat (total or saturated) and mortality.

Funding The authors have not declared a specific grant for this research from any funding agency in the public, commercial or not-for-profit sectors.

Competing interests $\mathrm{ZH}$ receives income from writing and from two small selfemployment businesses: The Harcombe Diet Co. and Columbus Publishing.

Provenance and peer review Not commissioned; externally peer reviewed.

ORCID ID

Zoe Harcombe http://orcid.org/0000-0003-3029-5850

\section{REFERENCES}

1 Select Committee on Nutrition and Human Needs. Dietary goals for the United States. 1st edn. Washington: U.S. Govt. Print, 1977.

2 National Advisory Committee on Nutritional Education (NACNE). A discussion paper on proposals for nutritional guidelines for health education in Britain. London: The Health Education Council, 1983

3 U.S. Department of Health and Human Services, Agriculture USDo. Dietary guidelines for americans. Washington: U.S. Government printing office, 1980.

4 U.S. Department of Health and Human Services and U.S. Department of agriculture 2015 - 2020 Dietary guidelines for Americans. 8th Edition. 2015 http://health.gov/ dietaryguidelines/2015/guidelines/

5 United States Department of Agriculture Center for Nutrition Policy and Promotion. Process to update the dietary guidelines. $2018 \mathrm{https} / / \mathrm{www}$. cnpp.usda.gov/dietaryguidelines (accessed 28th May 2018)
6 Harcombe Z, Baker JS, Davies B. Food for thought: have we been giving the wrong dietary advice? Food Nutr Sci 2013;04:240-4.

7 United States Department of Agriculture ARS. Oil, olive, salad or cooking, 2013.

8 United States Department of Agriculture ARS. Beef, bottom sirloin, tri-tip, separable lean only, trimmed to 0" fat, choice, raw [URMIS \#2244], 2013.

9 United States Department of Agriculture ARS. Pork, fresh, enhanced, loin, top loin (chops), boneless, separable lean and fat, raw, 2013.

10 United States Department of Agriculture ARS. Fish, mackerel, Atlantic, raw, 2013.

11 Barton S. Which clinical studies provide the best evidence? The best RCT still trumps the best observational study. BMJ 2000;321:255-6.

12 Burns PB, Rohrich RJ, Chung KC. The levels of evidence and their role in evidencebased medicine. Plast Reconstr Surg 2011;128:305-10.

13 Harcombe Z, Baker JS, Cooper SM, et al. Evidence from randomised controlled trials did not support the introduction of dietary fat guidelines in 1977 and 1983: a systematic review and meta-analysis. Open Heart 2015;2:e000196.

14 Harcombe Z, Baker JS, DiNicolantonio JJ, et al. Evidence from randomised controlled trials does not support current dietary fat guidelines: a systematic review and metaanalysis. Open Heart 2016;3:e000409.

15 Frantz ID, Dawson EA, Ashman PL, et al. Test of effect of lipid lowering by diet on cardiovascular risk. The Minnesota Coronary Survey. Arteriosclerosis 1989:9:129-35.

16 Harcombe Z, Baker JS, Davies B. Evidence from prospective cohort studies did not support the introduction of dietary fat guidelines in 1977 and 1983: a systematic review. Br J Sports Med 2017;51:1737-42.

17 Keys A. Coronary heart disease in seven countries. I. The study program and objectives. Circulation 1970:41(4 Suppl):11-8.

18 Harcombe Z, Baker JS, Davies B. Evidence from prospective cohort studies does not support current dietary fat guidelines: a systematic review and meta-analysis. $\mathrm{Br} J$ Sports Med 2017;51:1743-9.

19 SchwingshackI L, Hoffmann G. Dietary fatty acids in the secondary prevention of coronary heart disease: a systematic review, meta-analysis and meta-regression. BMJ Open 2014;4:e004487.

20 Hooper L, Summerbell CD, Thompson R, et al. Reduced or modified dietary fat for preventing cardiovascular disease. Cochrane database of systematic reviews 2011:7:CD002137.

21 Mozaffarian D, Micha R, Wallace S. Effects on coronary heart disease of increasing polyunsaturated fat in place of saturated fat: a systematic review and meta-analysis of randomized controlled trials. PLoS Med 2010;7:e1000252.

22 Siri-Tarino PW, Sun Q, Hu FB, et al. Meta-analysis of prospective cohort studies evaluating the association of saturated fat with cardiovascular disease. Am J Clin Nutr 2010;91:535-46.

23 Skeaff CM, Miller J. Dietary fat and coronary heart disease: summary of evidence from prospective cohort and randomised controlled trials. Ann Nutr Metab 2009:55:173-201.

24 Chowdhury R, Warnakula S, Kunutsor S, et al. Association of dietary, circulating, and supplement fatty acids with coronary risk: a systematic review and meta-analysis. Ann Intern Med 2014;160:398-406.

25 Harcombe Z. Dietary fat guidelines have no evidence base: where next for public health nutritional advice? Br I Sports Med 2017;51.

26 Ravnskov U, DiNicolantonio JJ, Harcombe Z, et al. The questionable benefits of exchanging saturated fat with polyunsaturated fat. Mayo Clin Proc 2014;89:451-3.

27 Rose GA, Thomson WB, Williams RT. Corn oil in treatment of ischaemic heart disease. Br Med J 1965;1:1531-3.

28 Woodhill JM, Palmer AJ, Leelarthaepin B, et al. Low fat, low cholesterol diet in secondary prevention of coronary heart disease. Adv Exp Med Biol 1978;109:317-30.

29 Turpeinen O, Karvonen MJ, Pekkarinen M, et al. Dietary prevention of coronary heart disease: the Finnish Mental Hospital Study. Int J Epidemiol 1979;8:99-118.

30 Hooper L, Martin N, Abdelhamid A, et al. Reduction in saturated fat intake for cardiovascular disease. Cochrane Database Syst Rev 2015;330.

31 Houtsmuller AJ, Zahn KJ, Henkes HE. Unsaturated fats and progression of diabetic retinopathy. Doc Ophthalmol 1980;48:363-71.

32 Black HS, Herd JA, Goldberg LH, et al. Effect of a low-fat diet on the incidence of actinic keratosis. N Eng/ J Med 1994;330:1272-5.

33 Moy TF, Yanek LR, Raqueño JV, et al. Dietary counseling for high blood cholesterol in families at risk of coronary disease. Prev Cardiol 2001;4:158-64.

34 Ley SJ, Metcalf PA, Scragg RK, et al. Long-term effects of a reduced fat diet intervention on cardiovascular disease risk factors in individuals with glucose intolerance. Diabetes Res Clin Pract 2004;63:103-12.

35 Dayton S, Pearce ML, HASHIMOTO S, et al. A controlled clinical trial of a diet high in unsaturated fat in preventing complications of atherosclerosis. Circulation 1969;40(1S2):II-1-0.

36 Burr ML, Gilbert JF, Holliday RM, et al. Effects of changes in fat, fish, and fibre intakes on death and myocardial reinfarction: diet and reinfarction trial (dart). The Lancet 1989;334:757-61.

37 Burr ML, Ashfield-Watt PA, Dunstan FD, et al. Lack of benefit of dietary advice to men with angina: results of a controlled trial. Eur I Clin Nutr 2003;57:193-200.

38 Schmitz $\mathrm{G}$, Ecker J. The opposing effects of $\mathrm{n}-3$ and $\mathrm{n}-6$ fatty acids. Prog Lipid Res 2008; $47: 147-55$ 
39 Sacks FM, Lichtenstein AH, Wu JHY, et al. Dietary fats and cardiovascular disease: a presidential advisory from the American Heart Association. Circulation 2017;136:e1-e23.

40 Teicholz N. The largest promoters of high-carb diets are funded by corporate interests: the nutrition coalition. $2018 \mathrm{https}: / /$ www.nutritioncoalition.us/2018/01/27/thelargest-promoters-of-high-carb-diets-are-funded-by-corporate-interests/ (accessed 9 Mar 2018).
41 Department of Health and Human Services (HHS). Dietary guidelines for americans: Department of Health and Human Services (HHS), 2010.

42 Fiolet T, Srour B, Sellem L, et al. Consumption of ultra-processed foods and cancer risk: results from NutriNet-Santé prospective cohort. BMJ 2018:360:k322.

43 Gowlett JAJ. What actually was the stone age diet? * J Nutr Environ Med 2003;13:143-7.

$\underline{\underline{\underline{C}}}$

$C$

$\frac{\infty}{8}$

の

$\stackrel{8}{\frac{1}{8}}$

竞

음

$\frac{\bar{\sigma}}{\bar{c}}$

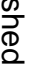

क

$\overrightarrow{0}$

$\overrightarrow{\vec{\omega}}$

बू

음. 